\title{
Pembrolizumab-induced fulminant type 1 diabetes with C-peptide persistence at first referral
}

\section{Kazuhisa Kusuki, Saya Suzuki and Yuzo Mizuno}

Department of Diabetes and Endocrinology, Kanto Central Hospital of the Mutual Aid Association of Public School Teachers, Setagaya-ku, Tokyo, Japan
Correspondence should be addressed to K Kusuki

Email

kusuki.k@gmail.com

\section{Summary}

A 72-year-old man with no history of diabetes was referred to our department due to hyperglycemia during pembrolizumab treatment for non-small-cell lung carcinoma. His blood glucose level was $209 \mathrm{mg} / \mathrm{dL}$, but he was not in a state of ketosis or ketoacidosis. Serum C-peptide levels persisted at first, but gradually decreased, and 18 days later, he was admitted to our hospital with diabetic ketoacidosis (DKA). The patient was diagnosed with fulminant type 1 diabetes (FT1D) induced by pembrolizumab. According to the literature, the insulin secretion capacity of a patient with type 1 diabetes (T1D) induced by anti-programmed cell death-1 (anti-PD-1) antibody is depleted in approximately 2 to 3 weeks, which is longer than that of typical FT1D. Patients with hyperglycemia and C-peptide persistence should be considered for hospitalization or frequent outpatient visits with insulin treatment because these could indicate the onset of lifethreatening FT1D induced by anti-PD-1 antibodies. Based on the clinical course of this patient and the literature, we suggest monitoring anti-PD-1 antibody-related T1D.

\section{Learning points:}

- Immune checkpoint inhibitors, such as anti-PD-1 antibodies, are increasingly used as anticancer drugs. Anti-PD-1 antibodies can cause immune-related adverse events, including T1D.

- FT1D, a novel subtype of T1D, is characterized by the abrupt onset of hyperglycemia with ketoacidosis, a relatively low glycated hemoglobin level and depletion of C-peptide level at onset.

- In patients being treated with anti-PD-1 antibody, hyperglycemia with C-peptide level persistence should be monitored through regular blood tests. Because of C-peptide persistence and mild hyperglycemia, it is possible to miss a diagnosis of life-threatening FT1D induced by anti-PD-1 antibody.

- In particular, in patients who have no history of diabetes, hyperglycemia without DKA is likely to be the very beginning of anti-PD-1 antibody-induced T1D. Therefore, such patients must be considered for either hospitalization or frequent outpatient visits with insulin injections and self-monitoring of blood glucose.

\section{Background}

Immune checkpoint inhibitors, such as anti-programmed cell death-1 (anti-PD-1) antibodies, are increasingly used as anticancer drugs. Cytotoxic T lymphocytes (CTLs) have an immune checkpoint function that checks whether they are attacking foreign substances in the body.
In short, they have a brake to control the immune system. PD-1 molecules are expressed on CTLs, and anti-PD-1 antibodies release the brake on the immune response, which enhances the anti-tumor immune response of CTLS (1). 
However, when the immune response to pancreatic $\beta$-cells runs out of control, type 1 diabetes (T1D) will develop. According to a Japanese survey, among patients who developed anti-PD-1 antibody-related T1D, 50\% met the criteria for fulminant type 1 diabetes (FT1D) (2). Anti-PD-1 antibody-related T1D often manifests as FT1D in Western countries as well $(3,4,5,6,7,8,9)$.

Typical FT1D patients usually develop diabetic ketoacidosis (DKA) or ketosis within 1 week after the onset of hyperglycemic symptoms, and C-peptide is markedly depleted when they present with DKA. Although most anti-PD-1 antibody-related T1D patients also present with DKA at the first referral, it should be noted that some of them present without DKA, having C-peptide level persistence when hyperglycemia is first discovered. This case report describes a case of pembrolizumab-induced FT1D in which the patient presented with asymptomatic hyperglycemia and C-peptide level persistence and developed DKA 18 days later.

\section{Case presentation}

A 72-year-old Japanese man who was undergoing pembrolizumab treatment for 4 months was admitted to our hospital as a result of DKA. Six years before the admission, he had undergone surgery for colon cancer. Three years previously, he also underwent two videoassisted thoracoscopic surgeries for lung metastasis. He was diagnosed with non-small-cell lung carcinoma 11 months before the present admission. ${ }^{18}$ Fluorodeoxyglucose PET/ CT showed increased ${ }^{18}$ fluorodeoxyglucose accumulation in the flank subcutaneous skin, ribs, erector spinal muscles, pancreatic head and intra-abdominal lymph nodes, which were considered to be metastases. Firstline carboplatin and pemetrexed were ineffective, then second-line pembrolizumab was started 4 months before the admission.

Six days before initiation of pembrolizumab treatment, a blood test found that his glycated hemoglobin (HbA1c) level was 5.6\% (reference range (RR): 4.6-6.2\%) and his casual blood glucose was $90 \mathrm{mg} / \mathrm{dL}$ (RR: 70-110 mg/dL). He had no personal or family history of diabetes, but his daughter was admitted to our hospital 8 years earlier as a result of thyroid storm and Graves' disease. He had smoked 30 cigarettes per day until the age of 70 but had now quit. He drank $550 \mathrm{~mL}$ of beer every day.

Transition of blood glucose and HbA1c values were as follows: casual blood glucose: $71 \mathrm{mg} / \mathrm{dL}$ and $\mathrm{HbA1c}$ : $5.6 \%, 3$ weeks after pembrolizumab induction: blood glucose was $88 \mathrm{mg} / \mathrm{dL}$ and HbA1c: 5.6\%, 6 weeks later: blood glucose was $72 \mathrm{mg} / \mathrm{dL}$ and HbA1c: 6.0\%, 12 weeks after.

At the end of the fifth course of pembrolizumab infusion (4 months after induction), his casual blood glucose was $209 \mathrm{mg} / \mathrm{dL}$ and HbA1c 6.4\%. He was referred to an endocrinologist the same day.

His physical condition was unremarkable, and he did not seem to be in a state of DKA. A C-peptide level of $2.77 \mathrm{ng} / \mathrm{mL}$ (RR: $0.8-2.5 \mathrm{ng} / \mathrm{mL}$ ) and a negative result for anti-glutamic acid decarboxylase (anti-GAD) antibody were obtained afterward by the same sample. The next week, his fasting plasma glucose level was $132 \mathrm{mg} / \mathrm{dL}$, C-peptide level $0.58 \mathrm{ng} / \mathrm{mL}$ and total ketone body level $665 \mu \mathrm{mol} / \mathrm{L}$ (normal range: $<131 \mu \mathrm{mol} / \mathrm{L}$ (outsourced blood test)). On the fifteenth day, the patient felt thirsty at home. His physical condition gradually worsened, his appetite decreased and he had difficulty moving. On the eighteenth day after the first referral, he revisited our hospital with his family.

He was $165 \mathrm{~cm}$ tall and weighed $46 \mathrm{~kg}$, with a BMI of 16.9 . He was alert, his body temperature was $36.6^{\circ} \mathrm{C}$, his blood pressure $133 / 74 \mathrm{mmHg}$, his pulse rate regular at $96 / \mathrm{min}$ and his oxygen saturation level was $93 \%$ while breathing ambient air. His breathing was 26 breaths per minute. Oral cavity and axilla were dry.

\section{Investigation}

Laboratory findings were as follows: plasma glucose: $488 \mathrm{mg} / \mathrm{dL}$; HbA1c: 8.1\%; C-peptide: $0.39 \mathrm{ng} / \mathrm{mL}$; 3-hydroxybutyric acid: $11200 \mu \mathrm{mol} / \mathrm{L}$; arterial blood gas pH: 7.12; Na: $140 \mathrm{mmol} / \mathrm{L}$; K: $6.15 \mathrm{mmol} / \mathrm{L}$; Cl: 100 $\mathrm{mmol} / \mathrm{L} ; \mathrm{HCO}_{3-}: 3.3 \mathrm{mmol} / \mathrm{L}$ and anion gap $(\mathrm{Na}-\mathrm{Cl}-$ $\left.\mathrm{HCO}_{3-}\right): 36.7 \mathrm{mmol} / \mathrm{L}$.

He was admitted to our hospital with a diagnosis of DKA. Serum amylase, lipase and elastase- 1 values were all within the normal limits. The patient had a haplotype of HLA DRB1*09:01-DQB1*03:03 which is significantly more frequent in autoimmune T1D and is also reported in anti-PD-1 antibody-related T1D $(10,11,12,13)$.

\section{Treatment}

The patient was diagnosed with FT1D on the basis of the abrupt onset of DKA within 1 week after appearance of diabetic symptoms and markedly depleted secretion of endocrine insulin. Since no prior infection was observed and pembrolizumab had been administered for 4 months, we took into consideration the onset of anti-PD-1 antibody-related FT1D. 
Dehydration was corrected with normal saline and continuous venous insulin infusion was initiated. On the third day of hospitalization, the patient started to have meals and continuous venous insulin infusion was switched to subcutaneous insulin injection. On the tenth day of hospitalization, a glucagon stimulation test was performed; C-peptide value before administration of 1 $\mathrm{mg}$ glucagon was $0.03 \mathrm{ng} / \mathrm{mL}$ and after was $0.04 \mathrm{ng} / \mathrm{mL}$. When the patient was discharged home on the eighteenth day of hospitalization, his fasting blood glucose level was about $130 \mathrm{mg} / \mathrm{dL}$, at three units of insulin degludec before sleep and (10-8-8) units of insulin lispro before each meal. His transitioning C-peptide levels at onset of T1D are shown in Fig. 1.

\section{Outcome and follow-up}

Following that, basal-bolus insulin therapy has been continued at the outpatient clinic for almost 2 years. There has been no recurrence of DKA. Fortunately, no recurrence of lung cancer has been observed.

\section{Discussion}

FT1D, a novel subtype of T1D, is characterized by the abrupt onset of hyperglycemia with ketoacidosis and a relatively low glycated hemoglobin level. In typical FT1D, insulin secretion capacity is markedly depleted within approximately 7 days after the onset of hyperglycemic symptoms. Present diagnostic criteria for FT1D require a depletion of C-peptide at the time of onset (fasting C-peptide $<0.3 \mathrm{ng} / \mathrm{mL}$; C-peptide after meal $<0.5 \mathrm{ng} / \mathrm{mL}$ and urinary C-peptide excretion $<10 \mu \mathrm{g} /$ day) (14).

There are increasing reports of patients presenting with T1D including FT1D induced by anti-PD-1 antibody.

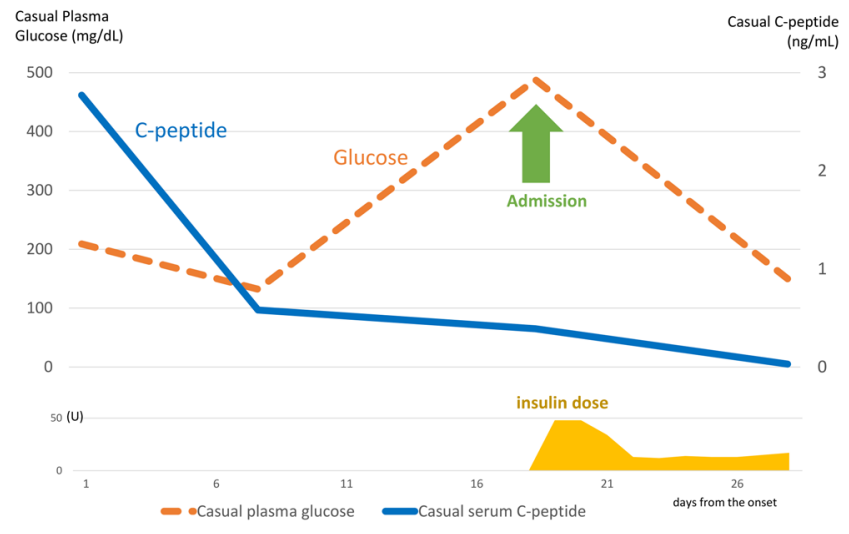

Figure 1

Transition of C-peptide values in this patient.
According to a recent report from the Japan Diabetes Society, the speed of the progression of $\beta$-cell destruction related to anti-PD-1 antibody treatment was slower than that of typical FT1D but faster than that of typical acuteonset T1D (2). That is, insulin secretion capacities in most of the patients receiving anti-PD-1 therapy were exhausted in 2 to 3 weeks after the onset of diabetes.

We think that anti-PD-1 antibody-induced T1D should be considered a subtype of diabetes distinct from spontaneous FT1D because the clinical course of anti-PD-1 antibody-induced diabetes is clearly slower than that of already known FT1D, the positive rate of anti-GAD antibodies is high, especially in Western PD-1induced diabetes (40\% for anti-PD-1 antibody-induced diabetes vs 9\% for spontaneous FT1D) and cases without elevated levels of pancreatic enzyme are often observed in Japanese and Western anti-PD-1 antibody-induced diabetes (47\% for anti-PD-1 antibody-induced diabetes vs $2 \%$ for spontaneous FT1D) (15).

In general, blood glucose tests are usually performed at the time of infusion of anti-PD-1 antibodies (once every 3 weeks for pembrolizumab, 2 weeks for nivolumab). Hyperglycemia can be diagnosed by these blood tests. In three case reports, when hyperglycemia was first diagnosed by regular blood tests, C-peptide levels were not depleted $(13,16,17)$. The periods from the onset of diabetes to depletion of C-peptide were 17 days in the case reported by Okamoto et al. (16), 12 days in the case reported by Yamamoto et al. (13) and 16 days in the case reported by Saito et al. (17). As for our patient, the period from the onset of hyperglycemia to DKA was 18 days, so the period until complete depletion of C-peptide was in the range of 18 to 28 days; therefore, the time course of this case was slightly longer than that of the other three cases in the previously mentioned studies.

Because of C-peptide persistence and mild hyperglycemia, it is possible to miss a diagnosis of lifethreatening FT1D induced by anti-PD-1 antibody. The Japan Diabetes Society recommends the following method for dealing with the onset of T1D in patients receiving immune checkpoint inhibitors: blood glucose level should be measured at every visit involving drug administration, and, if the patient has hyperglycemic symptoms or hyperglycemia (fasting blood glucose level of $126 \mathrm{mg} / \mathrm{dL}$ or higher, or casual blood glucose of 200 $\mathrm{mg} / \mathrm{dL}$ or higher), consultation with an endocrinologist is recommended for a definitive diagnosis of diabetes. If the patient is diagnosed with, or highly suspected of having, T1D, start insulin treatment that day. However, there is no specific indication for how to manage cases 
with hyperglycemia without DKA or C-peptide depletion. In particular, in patients with no history of diabetes, hyperglycemia without DKA is likely to be the very beginning of anti-PD-1 antibody-induced T1D. Therefore, it is highly recommended that patients suspected of having anti-PD-1 antibody-related T1D should be hospitalized; but, if they are not hospitalized, frequent outpatient visits after introducing insulin injection and self-monitoring of blood glucose should be considered.

In conclusion, we described a case of pembrolizumabinduced T1D; the patient was in the very early phase of $\beta$-cell destruction with C-peptide level persistence and presented with hyperglycemia without DKA. Such a patient is at a high risk for imminent DKA and should be considered for hospitalization or frequent monitoring as an outpatient. Many cases of anti-PD-1 antibodyinduced diabetes will indicate hyperglycemia on routine examination at the very beginning of diabetes, and our case is informative in considering the management of such patients, especially with regards to the right timing for patient hospitalization. In some cases, it is necessary to follow-up on an outpatient basis at least weekly. And, when DKA begins to develop, inpatient treatment must be started.

\section{Patient's perspective}

When the doctor told me that there was metastasis of lung cancer throughout my body, I did not feel bad and lived normally, and even after beginning anti-cancer treatment (authors' note: pembrolizumab), I did not really feel the effects of the drug. After that, it was explained to me that the imaging results showed an improvement, and I thought the drug would be effective. When I met you (author) for the first time, I heard that I had high blood sugar levels, which could possibly indicate type 1 diabetes, which was shocking news. There were no symptoms of diabetes on my first and second visits to you, but I began to experience thirstiness on the seventh day after my second visit. At first, it was not so bad, but I gradually lost my appetite and became unable to move, and 11 days after my second visit, my wife drove me to the hospital and I was hospitalized. I am doing my own insulin injections now but I do not think they are too troublesome. They have become a normal part of life.

\section{Declaration of interest}

The authors declare that there is no conflict of interest that could be perceived as prejudicing the impartiality of the research reported.

\section{Funding statement}

This research did not receive any specific grant from any funding agency in the public, commercial or not-for-profit sector.

\section{Patient consent}

Written informed consent has been obtained from the patient for publication of the submitted article.

\section{Author contribution statement}

$\mathrm{K} \mathrm{K}$ was the attending physician and had a central role in writing this manuscript. S S had an important discussion of this case in the department and presented this case in a study group. $Y \mathrm{M}$ advised on patient care and corrected this manuscript.

\section{References}

1 Iwai Y, Hamanishi J, Chamoto K \& Honjo T. Cancer immunotherapies targeting the PD-1 signaling pathway. Journal of Biomedical Science 201724 26. (https://doi.org/10.1186/s12929-0170329-9)

2 Baden MY, Imagawa A, Abiru N, Awata T, Ikegami H, Uchigata Y, Oikawa Y, Osawa H, Kajio H, Kawasaki E, et al. Characteristics and clinical course of type 1 diabetes mellitus related to antiprogrammed cell death-1 therapy. Diabetology International 201910 58-66. (https://doi.org/10.1007/s13340-018-0362-2)

3 Gaudy C, Clévy C, Monestier S, Dubois N, Préau Y, Mallet S, Richard MA, Grob JJ, Valéro R \& Béliard S. Anti-PD1 pembrolizumab can induce exceptional fulminant Type 1 diabetes. Diabetes Care 201538 e182-e183. (https://doi.org/10.2337/dc15-1331)

4 Chokr N, Farooq H \& Guadalupe E. Fulminant diabetes in a patient with advanced melanoma on nivolumab. Case Reports in Oncological Medicine 20182018 8981375. (https://doi. org/10.1155/2018/8981375)

5 Capitao R, Bello C, Fonseca R \& Saraiva C. New onset diabetes after nivolumab treatment.BMJ Case Reports 2018 2018. (https://doi. org/10.1136/bcr-2017-220999)

6 Chan JTK \& Jones E. Nivolumab-induced autoimmune diabetes. Journal of Pharmacy Practice and Research 201747 136-139. (https:// doi.org/10.1002/jppr.1247)

7 Zaied AA, Akturk HK, Joseph RW \& Lee AS. New-onset insulindependent diabetes due to nivolumab. Endocrinology, Diabetes and Metabolism Case Reports 20182018 17-0174. (https://doi. org/10.1530/EDM-17-0174)

8 Tzoulis P, Corbett RW, Ponnampalam S, Baker E, Heaton D, Doulgeraki T \& Stebbing J. Nivolumab-induced fulminant diabeticketoacidosis followed by thyroiditis. Endocrinology, Diabetes and Metabolism Case Reports 20182018 18-0111. (https://doi. org/10.1530/EDM-18-0111)

9 Abdullah HMA, Elnair R, Khan UI, Omar M \& Morey-Vargas OL. Rapid onset type-1 diabetes and diabetic ketoacidosis secondary to nivolumab immunotherapy: a review of existing literature. $B M$ ) Case Reports 201912 e229568. (https://doi.org/10.1136/bcr-2019229568)

10 Usui Y, Udagawa H, Matsumoto S, Imai K, Ohashi K, Ishibashi M, Kirita K, Umemura S, Yoh K, Niho S, et al. 1 Diabetes mellitus triggered by nivolumab in patients with non-small cell lung cancer. Thoracic Oncology 201712 e41-e43. (https://doi.org/10.1016/j. jtho.2016.12.015)

11 Kumagai R, Muramatsu A, Nakajima R, Fujii M, Kaino K, Katakura Y, Okumura N, Ohara G, Kagohashi K, Satoh H, et al. Acute-onset type 1 diabetes mellitus caused by nivolumab in a patient with advanced pulmonary adenocarcinoma. Journal of Diabetes Investigation $2017 \mathbf{8}$ 798-799. (https://doi.org/10.1111/jdi.12627)

12 Sakurai K, Niitsuma S, Sato R, Takahashi K \& Arihara Z. Painless thyroiditis and fulminant type 1 diabetes mellitus in a patient treated with an immune checkpoint inhibitor, nivolumab. Tohoku Journal of Experimental Medicine 2018244 33-40. (https://doi. org/10.1620/tjem.244.33)

13 Yamamoto N, Tsurutani Y, Katsuragawa S, Kubo H, Sunouchi T, Hirose R, Hoshino Y, Ichikawa M, Takiguchi T, Yukawa H, et al. A patient with nivolumab-related fulminant type 1 diabetes mellitus whose serum C-peptide level was preserved at the initial detection 
of hyperglycemia. Internal Medicine 201958 2825-2830. (https://doi. org/10.2169/internalmedicine.2780-19)

14 Imagawa A, Hanafusa T, Awata T, Ikegami H, Uchigata Y, Osawa $H$, Kawasaki E, Kawabata Y, Kobayashi T, Shimada A, et al. Report of the Committee of the Japan Diabetes Society on the Research of Fulminant and Acute-onset type 1 diabetes mellitus: new diagnostic criteria of fulminant type 1 diabetes mellitus (2012). Journal of Diabetes Investigation 20123 536-539. (https://doi.org/10.1111/ jdi.12024)

15 de Filette JMK, Pen JJ, Decoster L, Vissers T, Bravenboer B, Van der Auwera BJ, Gorus FK, Roep BO, Aspeslagh S, Neyns B, et al. Immune checkpoint inhibitors and type 1 diabetes mellitus: a case report and systematic review. European Journal of Endocrinology 2019181 363-374. (https://doi.org/10.1530/EJE-19-0291)

16 Okamoto M, Okamoto M, Gotoh K, Masaki T, Ozeki Y, Ando H, Anai M, Sato A, Yoshida Y, Ueda S, et al. Fulminant type 1 diabetes mellitus with anti-programmed cell death-1 therapy. Journal of Diabetes Investigation 20167 915-918. (https://doi.org/10.1111/ jdi.12531)

17 Saito D, Oikawa Y, Yano Y, Ikegami Y, Satomura A, Isshiki M, Kurihara S, Inoue I, Noda M \& Shimada A. Detailed time course of decline in serum C-peptide levels in anti-programmed cell death-1 therapy-induced fulminant Type 1 diabetes. Diabetes Care 201942 e40-e41. (https://doi.org/10.2337/dc18-1673)

Received in final form 19 March 2020

Accepted 7 April 2020 